\title{
Centro cultural dos povos da Amazônia: uma EXPERIÊNCIA PEDAGÓGICA VOLTADA PARA O ENSINO DE CIÊNCIAS
}

\author{
CULTURAL CENTER OF THE PEOPLES OF THE AMAZON: A PEDAGOGICAL \\ EXPERIENCE FOCUSED ON THE TEACHING OF SCIENCES
}

DOI: http://dx.doi.org/10.23926/RPD.2526-2149.2019.v4.n1.p302-316.id304

\section{Karoline Duarte Lopes \\ Mestrado em Ensino de \\ Ciências pela Universidade \\ do Estado do Amazonas \\ (UEA) \\ karolduartelopes@gmail.co \\ $\underline{\mathrm{m}}$}

\section{Hiléia Monteiro \\ Maciel Cabral}

Doutoranda em Ensino de

Ciências e Matemática

(UFMT)

Professora da Universidade

do Estado do Amazonas

(UEA)

hileiamaciel@gmail.com

\section{Cirlande Cabral da \\ Silva}

Doutorado em Ensino de

Ciências e Matemática

(UFMT)

Professor do Instituto

Federal de Educação,

Ciência e Tecnologia do

Amazonas (IFAM)

cirlandecabral@gmail.com
Resumo: Este trabalho relata uma experiência vivenciada durante o estágio docência do curso de Mestrado Acadêmico em Educação em Ciências na Amazônia desenvolvido com a turma de Licenciatura em Ciências Biológicas da Universidade do Estado do Amazonas, na disciplina Prática de Ensino de Biologia - Estágio Supervisionado IV, em uma aula prática realizada no Centro Cultural dos Povos da Amazônia, Manaus-AM. Esse relato de experiência tem como objetivo descrever como ocorreu a visita a esse espaço não formal e mostrar as possibilidades de ensinar ciências em um ambiente predominantemente histórico. A visita ao local possibilitou aos alunos condições de aprendizagem que habitualmente não haveria em sala de aula. Na visita realizada, criaram-se possibilidades de aumentar o conhecimento de todos acerca da história dos povos amazônicos associado de forma interdisciplinar aos conhecimentos científicos.

Palavras-chave: Relato de experiência; Centro Cultural dos Povos da Amazônia; Espaços não formais.

\begin{abstract}
This work reports an experience lived during the teaching stage of the Academic Master's Degree in Science Education in the Amazon developed with the group of Bachelor's Degree in Biological Sciences of the University of the State of Amazonas in the discipline Practice of Teaching of Biology - Supervised Internship IV in a practical class held at the Cultural Center of the Peoples of Amazonia, Manaus-AM. This report of experience aims to describe how the visit to this non-formal space took place and to show the possibilities of teaching science in a predominantly historical environment. The visit to the place made it possible for the students to learn conditions that they would not normally have in the classroom. During the visit, possibilities were created to increase the knowledge of all about the history of the Amazonian peoples associated in an interdisciplinary way with scientific knowledge.

Keywords: Experience report; Cultural Center of the Peoples of the Amazon; Non-formal spaces.
\end{abstract}




\section{INTRODUÇÃO}

É de suma importância refletir sobre as possibilidades de aprendizado em diferentes espaços educativos e incutir iniciativas educacionais nos futuros professores que visem explorar esses espaços fora da escola em especial para ensinar Ciências (MARANDINO; SELLES; FERREIRA, 2009).

Chassot (2003, p. 91) diz que "hoje não se pode mais conceber propostas para um ensino de Ciências sem incluir nos currículos componentes que estejam orientados na busca de aspectos sociais e pessoais dos estudantes".

Nesse sentido, o currículo escolar não deve ser proposto apenas para dentro do espaço escolar, mas pensado e realizado com o objetivo de abranger locais onde os alunos possam ter uma reflexão mais ampla do conhecimento acerca da natureza, dos ambientes ecológicos e do ensino de Ciências.

Sobre o ensino de Ciências acreditamos que este deve ir além do espaço escolar. Os espaços não formais podem fornecer recursos didáticos valiosos para o aprendizado, contribuindo de forma significativa para o ensino, já que no ambiente escolar, os professores quase sempre se limitam à proposta do livro didático.

Outra questão que deve ser levada em consideração é a formação dos professores, pois muitas vezes essa se apresenta deficiente, já que é comum o professor concluir o ensino superior sem a formação adequada para ensinar Ciências. Os cursos de formação de professores precisam se preocupar em preparar melhor os futuros docentes para que estes possam ensinar de forma significativa, por conseguinte, optar por conteúdos e métodos mais apropriados a fim de alcançar esse objetivo.

Considerando então a necessidade de privilegiar a dimensão prática dos espaços não formais nos cursos de formação de futuros professores durante o estágio docência, na Universidade do Estado do Amazonas (UEA), a professora da disciplina sugeriu fazermos uma visita ao Centro Cultural dos Povos da Amazônia com a turma de Licenciatura em Ciências Biológicas, a fim de evidenciar as possibilidades de ensinar Ciências fora da sala de aula.

O Centro Cultural dos Povos da Amazônia foi construído pelo Governo do Estado do Amazonas e encontra-se localizado na Bola da Suframa, na Praça Francisco Pereira da Silva e teve sua inauguração em maio de 2007. É um ambiente que prima pela valorização, divulgação e disseminação da história, da cultura e dos conhecimentos sobre os povos amazônicos. Assim, ao visitar este local, o objetivo foi de mostrar aos licenciandos que é possível ensinar Ciências 
por meio da interdisciplinaridade em um espaço não formal institucionalizado, predominantemente histórico.

\section{ESPAÇOS NÃO FORMAIS: CONTRIBUIÇÕES PARA O ENSINO DE CIÊNCIAS}

Trazemos aqui a definição de espaços não formais proposta por Jacobucci (2008, p. 55) quando afirma que estes são "lugares, diferentes da escola, onde é possível desenvolver atividades educativas". Ainda, segundo a autora, existem dois tipos de espaços não formais: Os espaços não formais institucionalizados, formados por uma equipe que se responsabiliza pelas atividades desenvolvidas no local e os não institucionalizados, aqueles que não apresentam uma estrutura institucional. Independentemente de ser institucionalizado ou não, os espaços não formais são considerados como fortes aliados dos professores, pois, facilitam a abordagem de conteúdos ou temáticas em um contexto real e mais dinâmico.

Falando acerca das contribuições dos espaços não formais para a educação, Maciel e Fachín-Terán (2014) acreditam que a educação não formal é motivadora e traz satisfação aos alunos pela experiência ímpar que estes locais possibilitam aos aprendizes.

As aulas de Ciências que acontecem em espaços não formais e em ambientes ao ar livre têm sido consideradas como metodologias eficazes (SENICIATO; CAVASSAN, 2004).

No entanto Gohn (2014) esclarece que a educação não formal não surgiu com o intuito de substituir o papel desempenhado pela educação formal, mas sim, para se tornar aliada a esta contribuindo para um melhor desenvolvimento do processo de ensino aprendizagem.

Muitas vezes o ensino não formal é proposto como um meio para superar as deficiências encontradas dentro da escola, como por exemplo, a falta de equipamento de laboratórios e a ineficiência da relação dos conceitos encontrados nos livros didáticos (BIANCONI; CARUSO, 2005).

O ensino de Ciências tem sido um grande desafio para os professores devido à dicotomia que envolve essa disciplina. Acerca disso, os Parâmetros Curriculares Nacionais de Ciências Naturais diz que:

\footnotetext{
A despeito de sua importância, do interesse que possa despertar e da variedade de temas que envolve, o ensino de Ciências Naturais tem sido frequentemente conduzido de forma desinteressante e pouco compreensível. A abordagem dos conhecimentos por meio de definições e classificações estanques que devem ser decoradas pelo estudante contraria as principais concepções de aprendizagem humana [...] (BRASIL, 1998, p. 26).
}

Ao transmitir conhecimentos sobre Ciências, é primordial não favorecer somente a memorização e, sim, fomentar circunstâncias que favoreçam o desenvolvimento cognitivo do 
aluno (VASCONCELOS; SOUTO, 2003). Os espaços não formais de educação auxiliam na conquista desse desenvolvimento progressivo de fatos e conhecimentos essenciais. (VIEIRA; BIANCONI; DIAS, 2005).

É preciso refletir na formação dos docentes que utilizam esses espaços de ensino, tais quais museus, centros de ciência e de cultura, "para que esses possam articular e entrecruzar a cultura científica, o saber popular e o próprio saber com vistas à criação de novos conhecimentos e a sua divulgação de forma consciente e cidadã” (JACOBUCCI, 2008, p. 64).

Outros motivos pelos quais o uso de estratégias didáticas em espaços não formais precisa ser fomentado é por estes oportunizarem a capacidade de raciocínio do aluno, a contribuição de superar as deficiências que permeiam o espaço escolar e a facilitação da real compreensão do nosso cotidiano (JACOBUCCI, 2008; SEIFFERT-SANTOS; FACHÍNTERÁN, 2013).

Pensando na utilização de espaços diversificados para o ensino de Ciências como estratégia diferenciada, foi proposto, durante o estágio docente do qual participei como aluna do mestrado, que conduzíssemos uma visita a um espaço não formal. Assim, a professora responsável pela disciplina propôs que intermediássemos uma visita a um espaço não formal com os alunos do $8^{\circ}$ período do Curso de Licenciatura em Ciências Biológicas da Universidade do Estado do Amazonas (UEA). No próximo tópico, falaremos acerca do lugar escolhido para a visitação dos futuros professores e de como ocorreu a visita a esse espaço.

\section{O Centro Cultural dos Povos da Amazônia: Ambiente Pedagógico para ENSINAR CIÊNCIAS?}

O Centro Cultural dos Povos da Amazônia - CCPA, através da Secretaria de Estado de Cultura, tem como finalidade pesquisar, valorizar, difundir e preservar as informações sobre os países da Amazônia Continental - Bolívia, Brasil, Colômbia, Equador, Guiana, Guiana Francesa, Peru, Suriname e Venezuela. Deste modo, dispõe à população informações relevantes através de exposições que representam e popularizam a cultura indígena e cabocla da Amazônia Continental ${ }^{1}$.

Adiante, faremos a descrição das experiências significativas possibilitadas pela visita ao Centro Cultural dos Povos da Amazônia (Figura 1) durante o estágio docência com a turma finalista ( $8^{\circ}$ período) de Licenciatura em Ciências Biológicas na disciplina Prática de Ensino de

\footnotetext{
${ }^{1}$ Informações retiradas do Portal da Cultura <Disponível em: http://www.cultura.am.gov.br/centro-cultural-dospovos-da-amazonia/>
} 
Biologia - Estágio Supervisionado IV. É importante destacar que a professora da disciplina Prática de Ensino de Biologia, por meio da coordenação do curso, enviou um documento ao Centro Cultural Povos da Amazônia solicitando permissão para a visitação da turma de estágio, no que foi prontamente atendida.

Este estudo apresenta relatos e reflexões acerca da experiência do estágio, nas quais, ocorreram diferentes situações que contribuíram para a aprendizagem e formação docente. Nesse sentido, concordamos com Santos et al. (2015) quando afirma que a experiência vivenciada durante o estágio nos proporciona momentos inusitados, com um vínculo de aproximação entre os estudantes, situação fundamental para facilitar o processo de ensino aprendizagem dos mesmos.

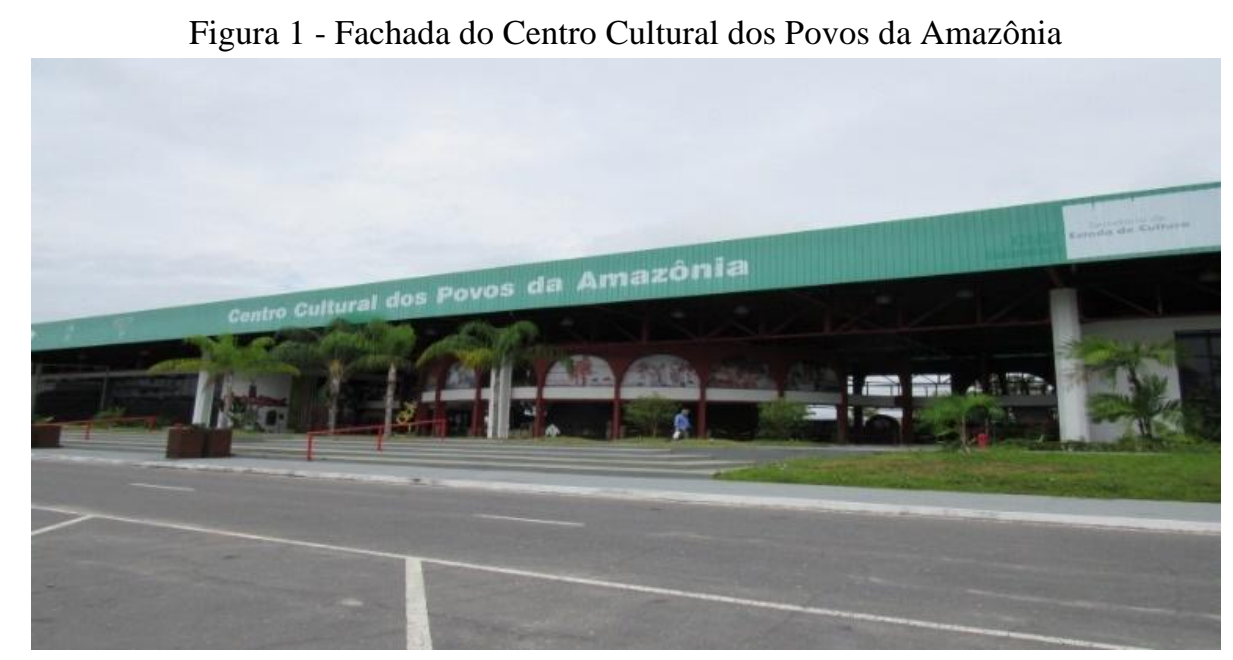

Fonte: Lopes, 2018

O ponto de encontro entre todos os envolvidos na visita (os 18 licenciandos, a professora de estágio e a mestranda) foi o próprio local da visita. Fomos bem recepcionados por funcionário do Centro Cultural o qual nos afirmou que esta foi a primeira vez que receberam a visita de uma turma de graduação, por isso pediram para tirar foto com a turma para guardarem em seus registros.

Às 9h00min, depois que todos chegaram ao local, foram passadas algumas orientações aos alunos graduandos a respeito de como ocorreria a atividade prática. Distribuímos o plano de aula que elaboramos, a pedido da professora responsável pela disciplina, para todos os alunos. O plano continha a justificativa, os objetivos da nossa ida ao local, bem como o roteiro de visitação.

O horário de funcionamento do CCPA é de segunda a sexta das $08 \mathrm{~h}$ às $14 \mathrm{~h}$. A entrada é gratuita para a população e o local disponibiliza guias bilíngues para o acompanhamento do 
público durante o roteiro de visitação. O espaço cultural possui 21 ambientes, dentre eles: Maloca Aruak, Casa do Caboclo, Moenda de Cana, Varal da Juta, Xapono Yanomami, Casa de Farinha, Barracão do Guaraná, Tapiri de Defumação da Borracha, Tapiri do Seringueiro, Canoas, Memorial e Biblioteca Arthur Reis, Memorial e biblioteca Mário Ypiranga Monteiro, Museu do Homem do Norte - Cine Silvino Santos, Biblioteca Arthur Reis, Passarelas dos Arcos, Espaço Rio Amazonas - cúpula de projeção (Exposição Os filhos de nossa terra), Auditório Gabriel Gentil, Reservas Técnicas 1, 2 e 3, Platibanda com ícones rupestres, Arena Cultural e Estúdio de Ensino a Distância- EAD.

Os monitores explicaram que nem todos os espaços estavam disponíveis para visitação naquele dia, por motivo de manutenção em algumas áreas. Ademais, os guias nos auxiliaram com os roteiros nas dependências do local, também foram responsáveis por explicar detalhes sobre a história e sobre a cultura do povo amazônico. Durante o trajeto, foram feitas algumas paradas estratégicas para que determinados temas fossem abordados com foco interdisciplinar, a fim de possibilitar que os alunos compreendessem não somente a história cultural da nossa região, mas também relacionassem os saberes adquiridos a conhecimentos científicos.

A visita se iniciou no próprio hall do Centro Cultural (Figura 2), onde existe uma canoa trabalhada artesanalmente, com pinturas retratando lendas regionais: Lenda do Boto, da CobraGrande, da Vitória Régia, da Iara. Os alunos da graduação conheciam algumas das histórias retratadas na peça artesanal e fizeram questão de contar para os colegas que desconheciam as narrativas. Criou-se uma oportunidade de resgatar as tradições que cercam o imaginário do amazônida. Acerca da abrangência do conceito de imaginário, Mendes (2016, p. 127) diz que esse pode ser "todas as representações, as formas de pensar e as experiências humanas. E para conhecê-las é preciso compreender também o sistema social, a economia, as culturas, as relações de classe, as formas de comunicação, entre outros aspectos". Ainda no hall existe uma construção, uma espécie de oca, chamada Cúpula de Projeções" (Figura 3). 
Figura 2 - Hall de entrada do Centro Cultural dos Povos da Amazônia

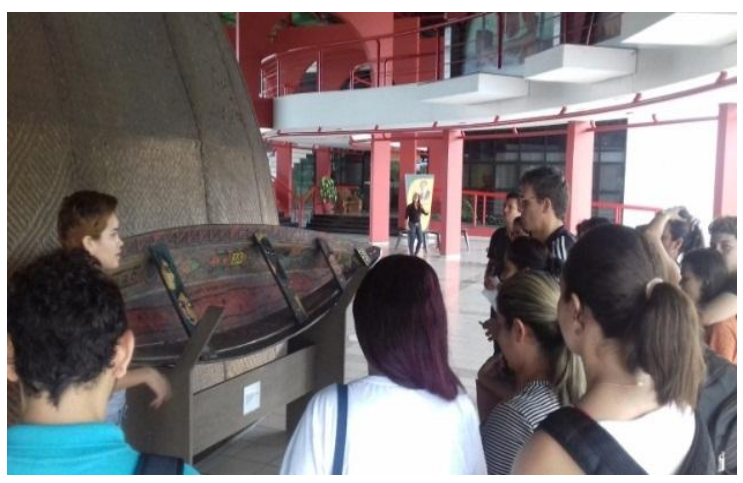

Fonte: Lopes, 2018.
Figura 3 - Cúpula de projeções

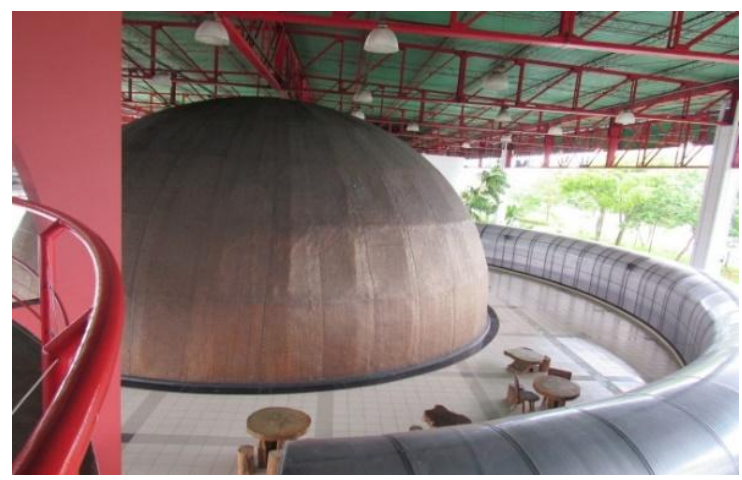

Fonte: Lopes, 2018.

Esta oca é revestida externamente por 36 tupés (tecidos com fibra de arumã) e foi confeccionada por artesãs da Associação de Artesãos de Novo Airão ${ }^{2}$ (AANA). Nesta oportunidade, pudemos citar algumas curiosidades sobre a fibra de arumã (Ischnosiphon polyphyllus) que são encontradas nas ilhas das Anavilhanas. Esta fibra é um tipo de cana com superfícies planas e que cresce em locais alagados. São utilizadas para confecção de artesanatos, cestarias e utensílios para uso próprio ou para comercialização (NAKAZONO; PIEDADE, 2004).

Neste momento, ressaltamos a excelente oportunidade que os licenciandos teriam de ensinar aos seus futuros alunos sobre o manejo e a sustentabilidade da extração da fibra de arumã.

$\mathrm{Na}$ esteira desse pensamento, concordamos com Junior e Noronha (2013) quando afirmam que o ensino de Ciências, enquanto processo de construção, deve se apropriar dos diversos espaços que constituem a vivência dos educandos, suscitando uma reflexão pautada em novas metodologias que visem a maior participação dos sujeitos que produzem o saber científico. Assim, percebe-se que as visitas a esses espaços não formais diversificados podem ser uma excelente oportunidade para se ensinar Ciências.

A seguir, encaminhamo-nos para o subsolo do Centro Cultural onde havia a Exposição "Filhos da Nossa Terra" (Figura 4), do escultor Felipe Lettersten. A coleção é constituída por um acervo de 18 esculturas (de diversas etnias). Os monumentos, feitos de fibra de vidro, são produzidos a partir de modelos vivos e homenageiam os povos nativos do mundo, perpetuando a sua existência através da reprodução de estátuas (Figura 5).

\footnotetext{
${ }^{2}$ Novo Airão é um município brasileiro do estado do Amazonas, distante $180 \mathrm{~km}$ da capital e possui uma população estimada em 18. 974 habitantes, segundo dados do IBGE de 2018.
} 


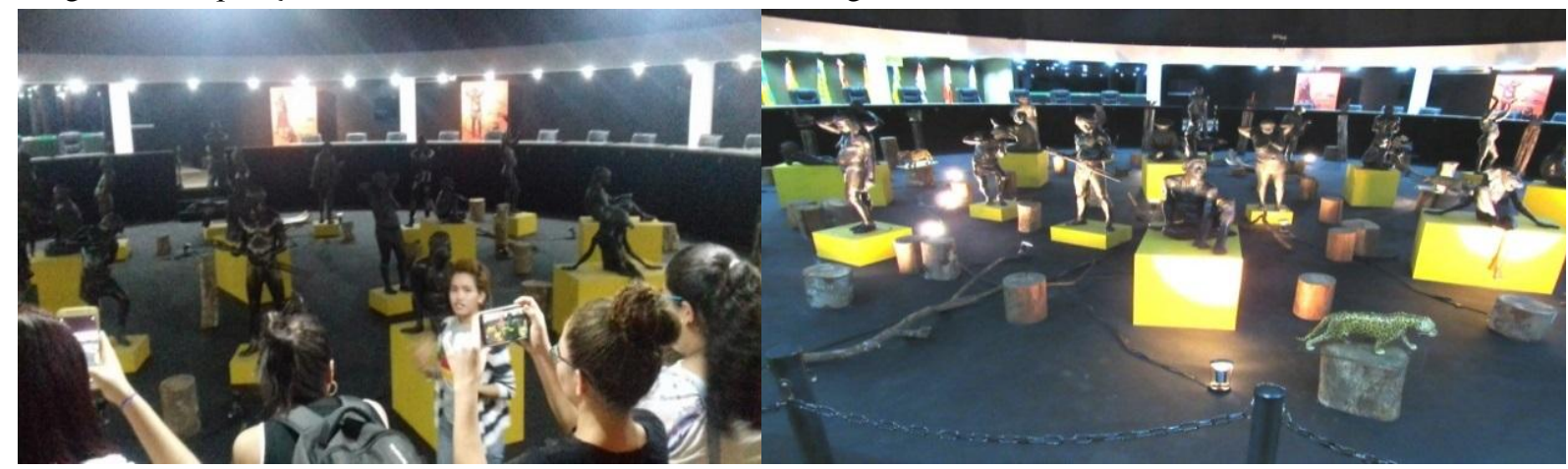

Fonte: Lopes, 2018.

Fonte: Lopes, 2018.

Os graduandos ficaram encantados com a reprodução real dos povos nativos, observaram a diferença de estilo no cabelo; o uso de indumentárias; comentaram sobre os hábitos relacionados aos trajes utilizados em determinado local e por determinada cultura e sobre os instrumentos de caça etc. Foi uma ocasião favorável para se discutir a grande diversidade que há entre os povos indígenas dependendo do país de onde se originam.

É nessa perspectiva histórico-cultural que concordamos com Vygotsky (2007) ao destacar a importância do contexto social do aluno para o processo de ensino, entendendo o indivíduo como um agente ativo no processo de criação de seu ambiente e não apenas como um produto de seu meio. Aliado a isso, compreendemos com Santos (2004) a importância do diálogo entre saberes: científicos, escolares e cotidianos.

Neste mesmo ambiente (citado acima), encontramos outra exposição do artista Turenko Beça "Bestiarii Venatio Animalia" contendo 11 obras que retratam animais da fauna amazônica (Figura 6).

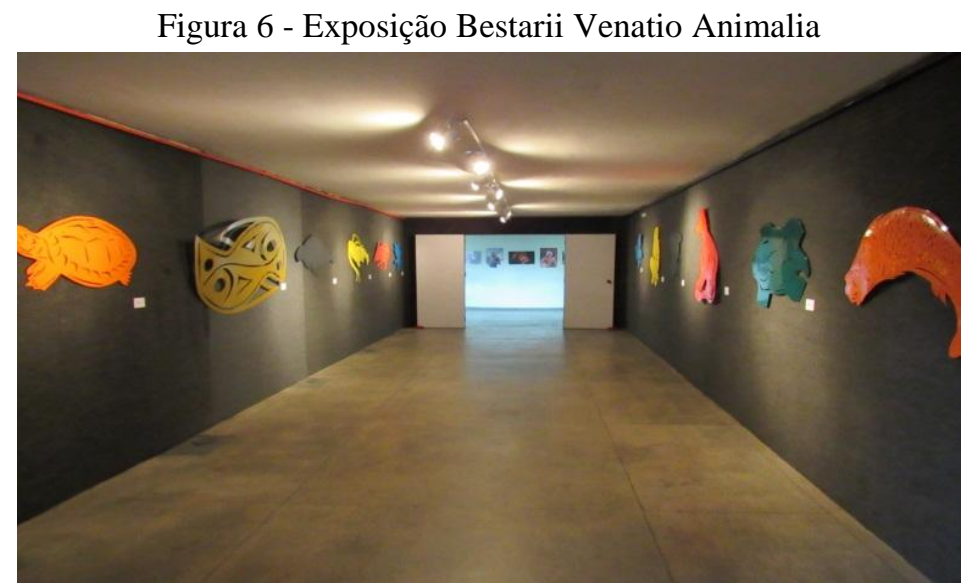

Fonte: Lopes, 2018.

Nesse local pedimos para os licenciandos observarem a placa de identificação que havia ao lado de cada animal representado na escultura e perguntamos o que, na concepção deles, 
estava faltando. Sem demora, responderam: "O nome científico das espécies!". Complementamos dizendo que eles poderiam, numa futura visita com seus alunos, ensinar, não somente o nome científico, mas também alguma curiosidade sobre os animais e aproveitar para falar quais ali estão vulneráveis à extinção.

Comentamos, por exemplo, sobre o piracuru (Arapaima gigas), maior peixe amazônico, cujo nome significa "Peixe Vermelho", em referência à cor da sua cauda. Ainda citamos que é um animal com risco de extinção devido à pesca predatória. Em seguida, os alunos começaram a falar quais nomes científicos eles lembravam: "Trichechus inunguis é o peixe boi, Arapaima gigas é o nome do pirarucu!". Ficou claro, que naquele ambiente havia muitas possibilidades de inserção de conhecimento científico aos alunos.

Após isso, fomos ao primeiro andar do Centro Cultural, visitar o chamado "Museu do Homem do Norte". Diria que foi o ponto alto de toda visita ao local devido ser um espaço com ambientes que retratam vários aspectos da cultura do homem amazônico (Figura 7). No primeiro ambiente há um mostruário de peças arqueológicas (vasos e utensílios), adereços e objetos indígenas (Figura 8).

Concordamos com Moreira e Candau (2003, p. 161) quando afirmam que "a escola sempre teve dificuldade em lidar com a pluralidade e com a diferença. Tende a silenciá-las e neutralizá-las. Sente-se mais confortável com a homogeneização e com a padronização". No entanto, com o momento atual e com as mudanças que vêm ocorrendo rapidamente no mundo contemporâneo, as questões culturais não podem ser ignoradas pelos educadores, pois a escola pode se distanciar cada vez mais das inquietações dos alunos (CANDAU, 2011). Assim, exigese que tal crise não seja enfrentada de forma superficial, mas de uma forma profunda, em que se possa romper com uma tendência homogeneizadora e monocultural que representa a escola nos dias de hoje. 
Figura 7 - Museu do Homem do Norte

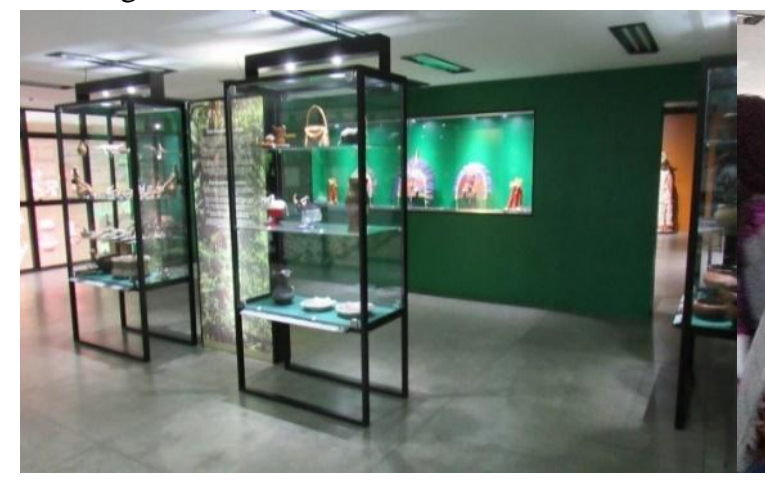

Fonte: Lopes, 2018.
Figura 8 - Guia explicando sobre os objetos indígenas

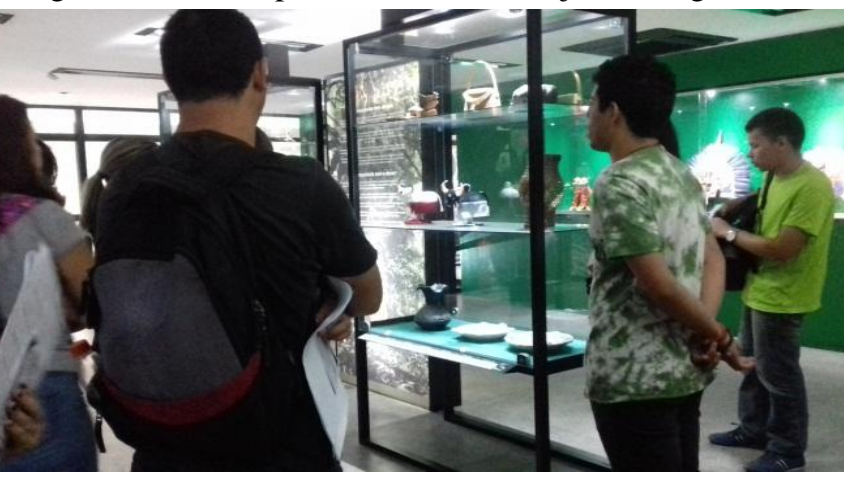

Fonte: Lopes, 2018.

No segundo ambiente, detalhes da cultura indígena são explicados pelos guias como o Ritual da Tucandeira da Tribo Sateré-Mawé e o Ritual da Moça Nova da Tribo Tikuna. Há também apresentação de vídeos mostrando algumas imagens dos costumes nativos. Os alunos se mostraram bem curiosos com relação aos rituais; percebemos um interesse em compreender a cultura totalmente oposta à nossa. Na ocasião, ressaltamos a importância de aprender e, acima de tudo, de valorizar a cultura do povo indígena.

Em outro ambiente encontramos uma exposição retratando a cultura do folclore tradicional e dos Festivais dos bois de Parintins/AM: Garantido e Caprichoso. Há vídeos com imagens do festival, assim como recurso multimídia de CDs players em que se pode ouvir as toadas dos bois de Parintins (Figura 9).

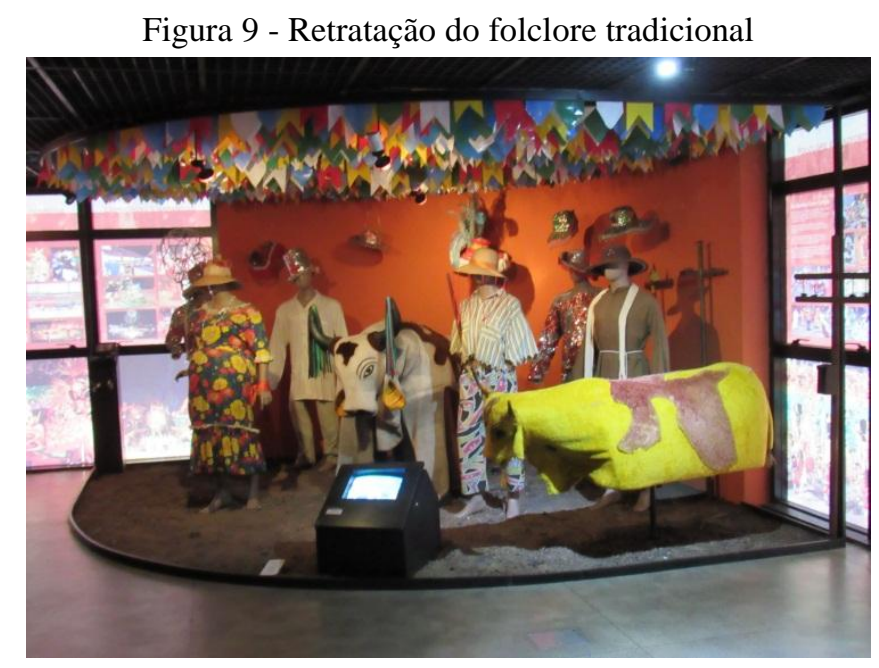

Fonte: Lopes, 2018.

Ainda nesse espaço há uma barraca com folhas dos principais chás utilizados na nossa região e, para a degustação dos visitantes, há uma garrafa térmica com um chá preparado. 
Encontramos também um mostruário com as frutas da região Amazônica e uma mesa com a demonstração de uma comida que faz parte do cardápio nortista: o tacacá.

Neste mesmo local, deparamo-nos com a exposição sobre o Extrativismo da Borracha, na qual aprendemos sobre a história dos seringueiros. Vimos utensílios utilizados na extração do látex e obtivemos informações sobre o Extrativismo da Castanha do Brasil. Neste momento, quando perguntamos qual o principal disseminador da castanha na floresta, os alunos responderam: "A cutia!” (Dasyprocta leporina). Surgindo então mais uma possibilidade de ensinar Ciências, falando acerca do papel importante que a cutia desempenha na natureza, que é o de plantar árvores e de que modo ela faz isso.

Depois de terminada a visita nos ambientes internos, passamos para a visita aos espaços externos do Centro Cultural. Dentre eles: o Tapiri de defumação da borracha (Figura 10), uma espécie de cabana de madeira coberta de palha, onde o seringueiro transforma o látex, retirado das seringueiras, em borracha para comercialização. No próprio local há um polímero de borracha real para que os alunos possam tocar e conhecer de perto o produto obtido a partir da seringueira (Figura 11).

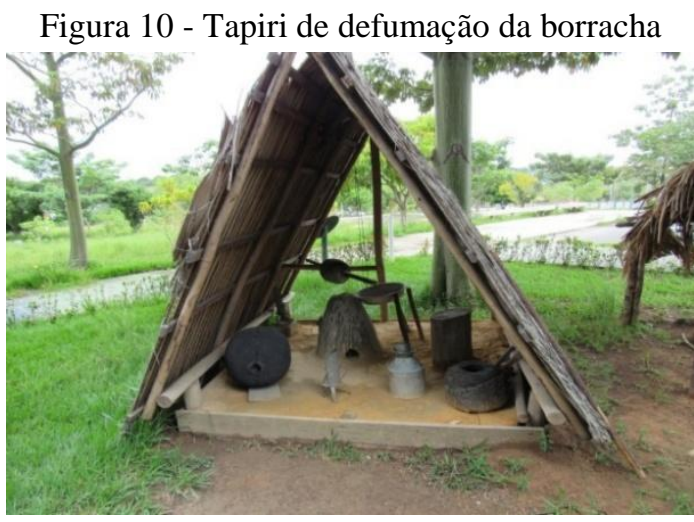

Fonte: Lopes, 2018.

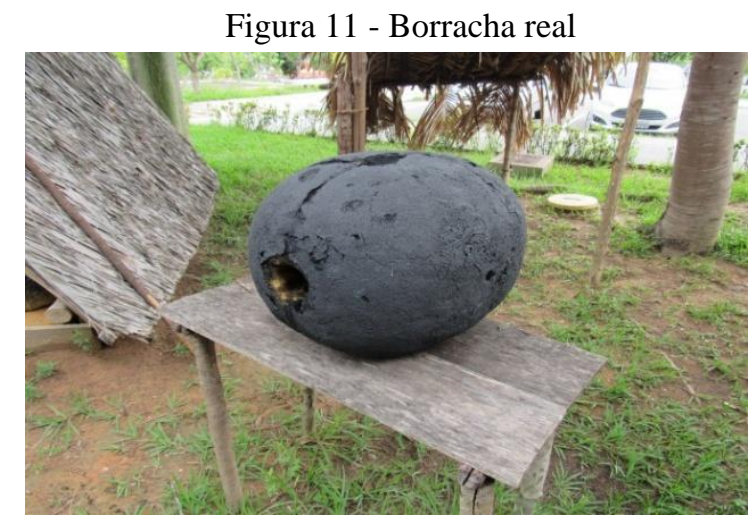

Fonte: Lopes, 2018.

Ainda na área do Centro Cultural que fica ao ar livre, encontramos a Casa de Farinha (Figura 12), ambiente que possibilitou aos alunos conversas sobre como ocorre o processo manual de fabricação da farinha. Este procedimento envolve várias técnicas herdadas dos povos indígenas da região. Vimos, ainda, o Barracão do Guaraná (Figura 13), onde aprendemos um pouco sobre a história e a lenda do guaraná. 
Figura 12 - Cada de farinha

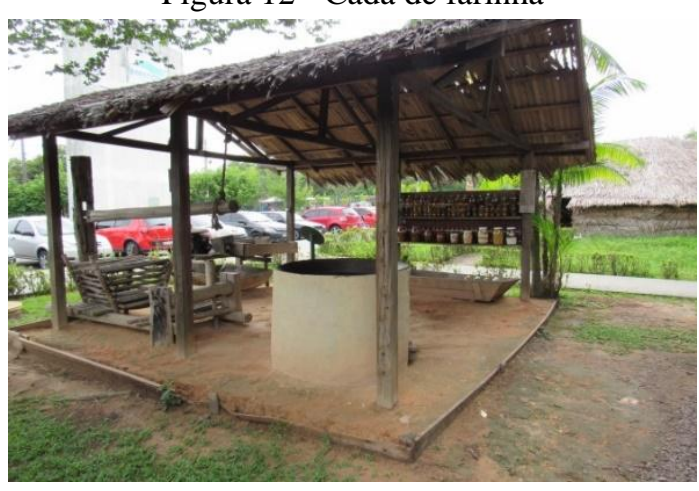

Fonte: Lopes, 2018.
Figura 13 - Barracão do Guaraná

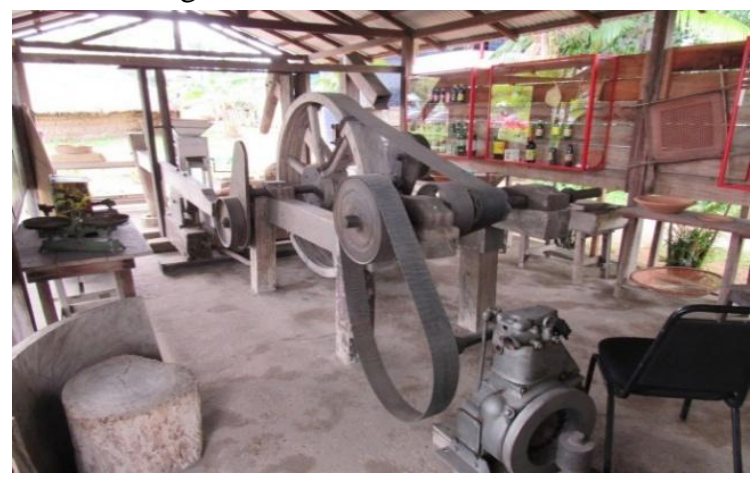

Fonte: Lopes, 2018.

Encontramos também a representação da Casa de Caboclo (Figura 14). Moradia simples de madeira de estilo rústico que possui utensílios e decoração típica das populações ribeirinhas. Ao adentrarmos nesse local, observamos uma mulher sentada em frente à janela, carregando um bebê no colo, logo atrás dela, uma rede de balanço. Nesta ambientação da casa do caboclo, o visitante tem a oportunidade de observar as peculiaridades de sua construção como o assoalho, feito com madeira lavrada ou tábua beneficiada, cuja presença de frestas é proposital para facilitar a limpeza e favorecer a ventilação.

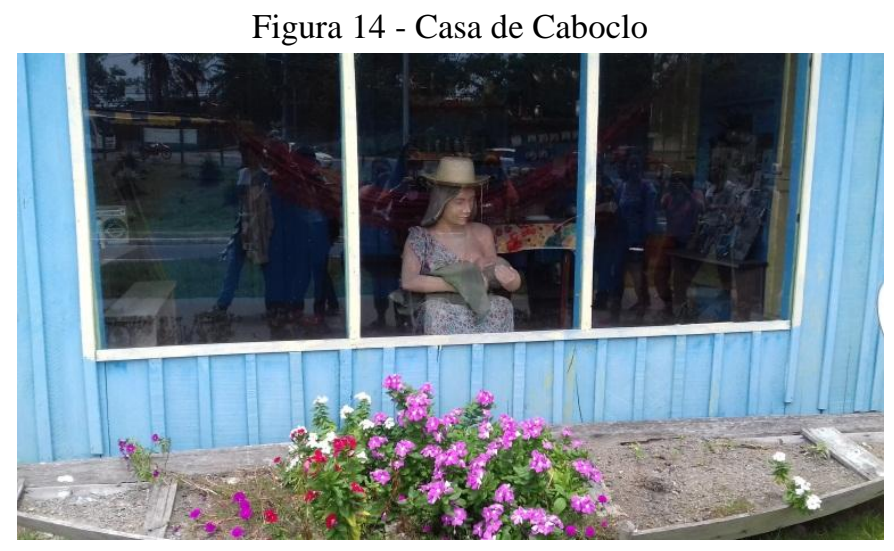

Fonte: Lopes, 2018.

Neste momento, a ambientação ao Centro Cultural é finalizada. Quando indagados sobre o que acharam dos espaços visitados, os futuros docentes disseram que gostaram de tudo que vivenciaram ali, que realmente há muitas possibilidades de ensinar Ciências e que futuramente anseiam levar seus próprios alunos para fazerem a mesma visita.

\section{CONSIDERAÇões FinAIS}

A educação formal e a não formal têm capacidade de serem grandes aliadas no processo de aprendizagem. Desta forma, espera-se que os espaços não formais estejam cada vez mais inseridos na cultura educacional do ensino de Ciências. 
É primordial estabelecer uma ligação entre a escola e esses espaços tidos como não formais de educação, a fim de que o ensino seja mais especulativo, envolvente e estimulante para os alunos, proporcionando a construção de uma consciência científica.

Os futuros docentes, ao terem contato com novas oportunidades de ensino de Ciências, percebem que há metodologias diferentes e possíveis de serem aplicadas aos seus futuros alunos, fugindo assim da aplicação de apenas o usual ensino tradicional em sala de aula.

Observamos que os espaços não formais, como o Centro Cultural dos Povos da Amazônia, propiciam aos alunos condições de aprendizagem que habitualmente não haveria em sala de aula. Na visita realizada, criaram-se possibilidades de aumentar o conhecimento de todos acerca da história do povo amazônico associado de forma interdisciplinar aos conhecimentos científicos.

A perspectiva da visita ao Centro Cultural exigiu uma contextualização dos temas trabalhados, pois necessitou fazer o diálogo entre a história da cultura do povo amazônico com conhecimentos científicos. Os futuros docentes conseguiram ver que é possível ensinar Ciências até mesmo em um ambiente predominantemente histórico.

Pontuamos a visita como uma excelente experiência de aprendizado, foi uma oportunidade de utilizar outros espaços para a aprendizagem dos graduandos, que não seja somente a sala de aula e serviu para problematizar como os espaços de educação não formal podem se complementar e auxiliar na construção da aprendizagem de seus futuros alunos.

Diante disso, destacamos a importância do Centro Cultural para a formação inicial dos alunos de Licenciatura em Ciências Biológicas da Universidade do Estado do Amazonas, sendo visto como um ambiente que favorece o ganho de experiências, promove dinamismo no momento da aprendizagem e possibilita a busca de novos métodos para ensinar Ciências.

\section{REFERÊNCIAS}

BIANCONI, M.; CARUSO, F. Educação não-formal. Revista Ciência e Cultura. São Paulo, v.57, n. 4, 2005. 20-20.

BRASIL. Secretaria de Educação Fundamental. Parâmetros curriculares nacionais: Ciências Naturais / Secretaria de Educação Fundamental. Brasília : MEC / SEF, 1998. 138 p.

CHASSOT, A. Alfabetização científica: uma possibilidade para a inclusão social. Revista Brasileira de Educação, Porto Alegre-RS. v. 2, n, 22, 2003. 89-100.

CANDAU, V. M. Diferenças culturais, cotidiano escolar e práticas pedagógicas. Currículo sem Fronteiras. v. 11, n. 2, p. 240-255, 2011. 
GOHN, M. G. Educação não formal, aprendizagens e saberes em processos participativos. Investigar em educação. II ${ }^{a}$ Série, número 1, 2014.

JACOBUCCI, D. F. C. Contribuições dos espaços não formais de educação para a formação da cultura científica. Em extensão, Uberlândia, v.7, 2008.

JUNIOR, J.C.L; NORONHA, E. L. A Feira Manaus Moderna: um espaço não-formal para o Ensino de Ciências. Atas do IX Encontro Nacional de Pesquisa em Educação em Ciências IX ENPEC, Águas de Lindóia, SP - 10 a 14 de Novembro de 2013.

MACIEL, H. M.; FACHÍN-TERÁN, A. O potencial pedagógico dos espaços não formais da cidade de Manaus. $1^{\text {a }}$. ed. Curitiba - PR: CRV, 2014.

MARANDINO, M.; SELLES, S.E.; FERREIRA, M.S. Ensino de Biologia histórias e práticas em diferentes espaços educativos. $1^{\text {a }}$ ed. São Paulo: Cortez, 2009.

MOREIRA, A. F. B.; CANDAU, V. M. Educação escolar e cultura (s): construindo caminhos. Revista Brasileira de Educação, Porto Alegre-RS, v. 2 n. 23, p. 156-168, 2003.

MENDES, F. M. M. Imaginário na Amazônia: os diálogos entre história e literatura / Francielle Maria Modesto Mendes. - Rio Branco: Edufac, 2016. 198 p.

NAKAZONO, E. M.; PIEDADE, M. T. F. Biologia e ecologia do arumã, Ischnosiphon polyphyllus (Marantaceae), no Arquipélago de Anavilhanas, Rio Negro, Amazônia Central. Revista Brasileira de Botânica. São Paulo, v. 27, n.1, 2004. 421-428.

SANTOS, B. de S. Um discurso sobre as ciências. 2 ed. São Paulo: Cortez, 2004.

SANTOS, G. S.; BARROS, G. R. O.; NUNES, M. A. A.; MARQUES, A. M. I Congresso de Inovação Tecnológica em Arapiraca - VII Seminário de Estágio: perspectivas atuais dos profissionais em educação. Universidade Federal de Alagoas-Arapiraca, 2015. Disponível em: http://www.seer.ufal.br/index.php/cipar/article/download/1898/1397. Acesso em: 29 março 2019.

SEIFFERT-SANTOS, S. C.; FACHÍN-TERÁN, A. O uso da expressão Espaços não-formais no Ensino de Ciências. Revista Areté, Manaus-AM, v. 6, n.2, 2013. 01-15.

SENICIATO, T.; CAVASSAN, O. Aulas de Campo em Ambientes Naturais e Aprendizagem em Ciências - Um Estudo com Alunos do Ensino Fundamental. Revista Ciência \& Educação. v. 10, n.3, 2004. 133-147.

VASCONCELOS, S.D.; SOUTO, E. O livro didático de ciências no ensino fundamental proposta de critérios para análise do conteúdo zoológico. Revista Ciência \& Educação, v. 9, n.1, 2003. 93-104.

VIEIRA, V.; BIANCONI, M. L.; DIAS, M. Espaços não-formais de ensino e o currículo de ciências. Revista Ciência e Cultura, São Paulo, v. 57, n.4, 2005. 21-23. 
VYGOTSKY, L. S. A Formação Social da Mente: o desenvolvimento dos processos psicológicos superiores. 7 ed. São Paulo: Martins Fontes, 2007.

Recebido em: 17 de outubro de 2018.

Aprovado em: 07 de abril de 2019. 